\title{
$\infty \sqrt{1}$ Stroke and Vascular Neurology \\ Opening already occluded middle cerebral artery, internal carotid artery or other cerebral arteries: when, where, how and why?
}

David Wang, ${ }^{1,2}$ Yongjun Wang ${ }^{3,4}$

To cite: Wang D, Wang Y. Opening already occluded middle cerebral artery, internal carotid artery or other cerebral arteries: when, where, how and why?. Stroke and Vascular Neurology 2017;2: e000107. doi:10.1136/svn-2017-000107

Received 7 August 2017 Accepted 8 August 2017 Published Online First 24 August 2017

\section{SLinked}

- http://dx.doi.org/10.1136/ svn-2017-000086

- http://dx.doi.org/10.1136/ svn-2017-000089

\section{CrossMark}

${ }^{1}$ OSF/INI Stroke Network and Comprehensive Stroke Center, OSF Saint Francis Medical Center, Peoria, Illinois, USA ${ }^{2}$ Department of Neurology, University of Illinois College of Medicine at Peoria, Peoria, Illinois, USA

${ }^{3}$ China National Clinical Research Center for Neurological Diseases, Beijing, China

${ }^{4}$ Department of Neurology, Beijing Tiantan Hospital, Capital Medical University, Beijing, China

Correspondence to Professor David Wang; david.wang@chinastroke.net
Time is of essence in saving brain cells in patients with acute ischaemic stroke, the faster the treatment, the better the outcome. The time window for intravenous tissue plasminogen activator (tPA) treatment is $<3$ hours. With the recent success of multiple bridging trials, the treatment time window has been opened up to $6-8$ hours. In fact, both Therapy in the Treatment of Acute Stroke Due to Anterior Circulation Large Vessel Occlusion Presenting within Eight Hours of Symptom Onset and Endovascular Treatment for Small Core and Anterior Circulation Proximal Occlusion with Emphasis on Minimizing CT to Recanalization Times trials have treated patients between 8 and 12 hours from the onset. ${ }^{12}$ We know that the number needed to treat (NNT) to have the benefit for intravenous tPA is 1 in 3 . In bridging therapy, intravenous tPA plus intra-arterial thrombectomy within 6 hours of onset, the NNT is 1 in 2-4. Most recently, two trials reported successful expansion of treatment window beyond 12 hours. CT Perfusion to Predict Response to Recanalization in Ischemic Stroke Project study reported that intra-arterial thrombectomy was effective in treating patients with acute ischaemic stroke within 18 hours of onset. $^{3}$ The Diffusion Weighted Imaging (DWI) or Computerized Tomography Perfusion (CTP) Assessment With Clinical Mismatch in the Triage of Wake Up and Late Presenting Strokes Undergoing Neurointervention (DAWN) trial reported that intra-arterial thrombectomy would bring similar benefit in selected patients who had a stroke within 24 hours of onset. ${ }^{4}$ DAWN has given thousands of patients with wake-up strokes the hope of having their occluded large cerebral arteries recanalised. These important breakthroughs in acute ischaemic stroke treatment have again changed the pathways and paradigm of clinical practice and saved many brains and lives.

However, on the other hand, there is still controversy on how to effectively and safely treat subacute or chronic intracranial or extracranial large cerebral arterial occlusions. ${ }^{5}$ Despite the ability of the brain to compensate under chronic hypoperfusion or hypoxia, patients with these conditions often do not perform well clinically. They often complain of loss of 'mental power', worsening of memory, inability to concentrate, difficulty performing their jobs, lack of stamina and trouble carrying on with their activities of daily living. These patients also have a higher stroke recurrent rate (up to $35 \%$ ) and a chance to occlude the contralateral carotid artery. ${ }^{6-11}$ Research is still ongoing on how to treat these patients properly. Many are concerned with the attempt to open these already occluded arteries owing to the fear of reperfusion injury or worsening of stroke. It is also unclear if such intervention could bring any clinical benefit. The Carotid Occlusion Surgery Study has certainly reminded us that even with external carotid artery to internal carotid artery bypass, the outcome was less than ideal. ${ }^{12}$

In this issue of $S V N$, two articles from two different groups in China reported their experiences in opening up already closed large cerebral arteries. Chen and Shi $e t a l^{33}$ reported 16 cases of successful recanalisation of the closed middle cerebral arteries (MCAs) in the subacute and chronic stages. The average NIHSS score in these patients was 7 prior to the intervention. Their MCAs were successfully reopened in all but one by balloon angioplasty with or without stenting. One case was treated within 90 days of stroke. Ten patients had modified Rankin Scale score between 0 and 1 at 3 months. Although the 
series was small, it offered some evidence that late recanalisation of occluded MCA was possible.

Zhang et $a l^{14}$ reported 10 cases of surgically removing the occluded carotid stents that were used initially to treat carotid stenosis. Under this circumstance of recurring stenosis or near occlusion of stented carotid artery, the common approach is to perform balloon angioplasty inside the stenotic stent. Surgically removing the stent via carotid endarterectomy has rarely been performed. During the operation, no bypass or tissue patching was needed, instead, the artery was sutured together once the stent and plaque were removed. In these cases, the vessels remained patent for more than a year. Although this was a small series and has not been tested in a prospective trial, the attempt has demonstrated two levels of significance: the safety and effectiveness of removing the occluded stent and the feasibility of opening chronically occluded carotid arteries.

These two exploratory small sample series were enlightening to opportunities of clinical research and current clinical practice. Their experiences may have helped 'crack the window open' into the chronic phase when considering recanalisation strategy of occluded cerebral arteries in subacute and chronic phases. From the pathophysiology point of view, in patient with acute ischaemic stroke, good prognosis or recovery relies on the preservation of penumbra and re-establishing blood flow. However, before normal perfusion is re-established, the 'survival' of penumbra relies on the presence of collateral circulation. ${ }^{15}$ Literature has reported that penumbra could still be present even after 24 hours of ischaemia. ${ }^{16}$ Despite controversy, it seemed that re-establishing cerebral perfusion at any stage of occlusion could help patients who had a stroke. However, the success may rely on how the patients are selected. In both series, multimodal imaging studies were used to carefully choose the candidates for treatment. With the modern imaging technology, we have seen the DAWN of opening up acutely occluded large cerebral arteries within 24 hours. The time to successfully recanalise subacute or chronically occluded large cerebral arteries may have just arrived.

Competing interests None declared.

Provenance and peer review Commissioned; internally peer reviewed.
Open Access This is an Open Access article distributed in accordance with the Creative Commons Attribution Non Commercial (CC BY-NC 4.0) license, which permits others to distribute, remix, adapt, build upon this work non-commercially, and license their derivative works on different terms, provided the original work is properly cited and the use is non-commercial. See: http://creativecommons.org/ licenses/by-nc/4.0/

(c) Article author(s) (or their employer(s) unless otherwise stated in the text of the article) 2017. All rights reserved. No commercial use is permitted unless otherwise expressly granted.

\section{REFERENCES}

1 Jovin TG, Chamorro A, Cobo E, et al. Thrombectomy within 8 hours after symptom onset in ischemic stroke. $N$ Engl J Med 2015;372:2296-306.

2 Goyal M, Demchuk AM, Menon BK, et al. Randomized assessment of rapid endovascular treatment of ischemic stroke. $N$ Engl J Med 2015;372:1019-30.

3 Lansberg MG, Christensen S, Kemp S, et al. Computed tomographic perfusion to predict response to recanalization in ischemic stroke. Ann Neurol 2017;81:849-56.

4 DAWN: Thrombectomy Effective Up to 24 Hours After Stroke Medscape. 2017.

5 Jordan BP, Mayschak DT, Flye MW. Treatment of the totally occluded carotid artery. Arch Surg 1984;119:952-5.

6 Webster MW, Makaroun MS, Steed DL, et al. Compromised cerebral blood flow reactivity is a predictor of stroke in patients with symptomatic carotid artery occlusive disease. J Vasc Surg 1995;21:338-45.

7 Kuroda S, Houkin K, Kamiyama H, et al. Long-term prognosis of medically treated patients with internal carotid or middle cerebral artery occlusion: can acetazolamide test predict it? Stroke 2001;32:2110-6.

8 Barber PA, Davis AM, Darby DG, et al. Absent middle cerebral artery flow predicts the presence and evolution of ischemic penumbra neurology. Stroke 1999;52:1125-32.

9 Webster MW, Makaroun MS, Steed DL, et al. Compromised cerebral blood flow reactivity is a predictor of stroke in patients with symptomatic carotid artery occlusive disease. J Vasc Surg 1995;21:338-45.

10 Gupta A, Chazen JL, Hartman M, et al. Cerebrovascular reserve and stroke risk in patients with carotid stenosis or occlusion: a systematic review and meta-analysis. Stroke 2012;43:2884-91.

11 Barnett HJ. Delayed cerebral ischemic episodes distal to occlusion of major cerebral arteries. Neurology 1978;28:769-74.

12 Powers WJ, Clarke WR, Grubb RL, et al. Extracranial-intracrania bypass surgery for stroke prevention in hemodynamic cerebral ischemia: the carotid occlusion surgery study randomized trial. JAMA 2011;306:1983-924.

13 Shi S, Chen S, HouX, et al. The efficacy and safety of endovascular recanalization of occluded large cerebral arteries during the subacute phase of cerebral infarction, a case series report. SVN 2017.

14 Yu L-B, Yan W, Zhang Q, et al. Carotid endarterectomy for treatment of Carotid in-stent restenosis: long-term follow-up results and surgery-experiences from one single center. SVN 2017.

15 Neumann-Haefelin T, Wittsack HJ, Wenserski F, et al. Diffusion- and perfusion-weighted MRI. The DWI/PWI mismatch region in acute stroke. Stroke 1999;30:1591-7.

16 Yamauchi $\mathrm{H}$, Fukuyama $\mathrm{H}$, Nagahama $\mathrm{Y}$, et al. Evidence of misery perfusion and risk for recurrent stroke in major cerebral arterial occlusive diseases from PET. J Neurol Neurosurg Psychiatry 1996;61:18-25. 